\title{
Student's Ownership Of Class Project Improves Learning
}

\author{
Aiman S. Kuzmar, Ph. D., P. E. \\ The Pennsylvania State University
}

\begin{abstract}
An alternative approach to the project assignment process in the Steel and Reinforced Construction courses (AET 214 and AET 215 respectively) in the Architectural Engineering Technology Program at Penn State Fayette, The Eberly Campus was introduced and implemented in the past four years. Instead of dictating the project topic by the instructor, the students were given the freedom to choose their own topics with a few necessary restrictions.

This paper gives details on this alternative approach. As usual, there are advantages and shortcomings. This paper outlines these positive and negative elements in addition to suggestions to improve the new approach. Over a four-year period, the students chose a wide variety of topics. The students became creative in this regard. The appendices of this paper list these topics. The paper offers an evaluation of this alternative approach through instructor's observations and students' comments. Embedded in the paper is a comparison between this alternative approach and the traditional way of assigning course projects.
\end{abstract}

\section{Introduction}

Several educators have reported that the implementation of new and alternative teaching methods improves learning by students ${ }^{1-5}$. In engineering and engineering technology education, the ASEE supports this by making new teaching techniques as one of the topics in its annual conference as well as in its annual chapter conferences ${ }^{6}$. Several alternative teaching techniques have been implemented in the specific courses of steel and concrete in civil engineering and civil engineering technology education ${ }^{7,8}$.

Many courses in almost all disciplines, from Sociology ${ }^{9}$ to English $^{10}$, require a term project and consider it an important part for various reasons. This is true in almost all engineering and engineering technology fields including steel and concrete construction courses. A traditional format for assigning the project in these two particular courses was used in the Engineering Technology Program at Penn State Fayette, The Eberly Campus prior to the year 2001. A different approach in assigning the course project in these two courses has been implemented since 2001. A brief description of the traditional approach is given next followed by a detailed outline of the new approach including highlights on how the switch between the two formats led to improvements in the learning process.

\section{The importance of course projects}

In a typical course, the instructor teaches students a set of related theories and concepts, one theory or concept at time over a fifteen-week period. Short assignments are usually

"Proceedings of the 2005 American Society of Engineering Education Annual Conference \& Exposition Copyright (C) 2005. American Society of Engineering education" 
given on a weekly basis. The primary objective of these short and frequent assignments is to help students understand the theory or the concept, which is covered during a particular week. Another objective is to compile a grading profile for each student. This later objective should be viewed as important by both the student and the instructor in only one sense. The student must use it to improve his or her learning. On one hand, if the grade of the assignment is satisfactory, the student must continue his or her learning process in positive ways. On the other hand, if the grade is poor, then the student must use this as a warning sign to start improving his or her learning. The instructor has an important role in this regard as follows. The instructor should help students with poor short-term grades to improve their learning process in addition to improving his or her own teaching process.

Typically, the individual theories and concepts making up a given course as described above are connected by virtue of belonging to the same course. The degree of this fusion varies between disciplines and even between courses in the same discipline. It ranges from minimal in a few cases to strong in other cases. Integrating all of these individualized but related theories and concepts can be accomplished by assigning a course project or a term paper. As mentioned earlier, many disciplines use the project method in their education ${ }^{9,10}$. The course project has also an evaluation role similar to that of the short assignments as described above, but on a larger scale.

The project in the engineering and engineering technology courses shares equal importance with other disciplines. This includes steel and concrete courses which are in the focal point of this paper.

\section{The traditional approach of assigning projects in steel and concrete courses at Penn State Fayette, the Eberly Campus}

In steel and concrete construction courses, the instructor teaches the students a variety of topics. These topics include steel and concrete as constructions materials. The topics also include the design and analysis of the main structural components like beams, columns, slabs, joists, decks, connections, and footings. Additionally, the topics include detailing all of the above structural components. The instructor starts typically with a brief theoretical background. The application of this theoretical introduction is usually followed by solving real or close to real life applications like designing a beam, a column base plate, or a footing. In many cases, design aids are available for students to perform this task. This may include tables, charts or computer programs.

A common practice among instructors is to assign a project at the end of these courses. The essential function of such a project is to integrate what the students learn in bits and pieces throughout the term into one big task at its end. The main objective of this project assignment is to make the learning process more effective.

In these two specific cases of concrete and steel construction courses, the instructor asks students to design a large structure ${ }^{11,12}$. This includes designing and detailing floors, beams, columns, and footings. In this traditional approach of assigning the project, the

"Proceedings of the 2005 American Society of Engineering Education Annual Conference \& Exposition Copyright (C) 2005. American Society of Engineering education" 
students do not have a choice except to follow instructions. In some cases, students work in teams. Sometimes, the instructor requires the group to present their work to the class at the end of the course. This was followed by the instructors at Penn State Fayette, The Eberly Campus before an alternative method was introduced in 2001 as outlined later.

In essence, this traditional approach dictates the topic to the students. It gives them instructions on how to proceed. It asks the students to repeat what they have already performed in a collective way though. Due to its long and time-consuming nature, a group of students is asked to work on a single project. It is not uncommon at all to notice that only one or two students perform the work while other group members claim credit for it. Those who perform the work benefit and learn from the project while those who stand by do not. There are ways to prevent this from happening but they require extra efforts from the instructor and the students.

\section{An alternative approach of assigning projects in steel and concrete courses at Penn State Fayette, the Eberly Campus}

An alternative approach to assign course projects is available to improve learning and to address some of the concerns associated with the traditional approach as described above. Basically, the instructor gives the students the freedom to choose their own topics for the course project with a few necessary constraints.

This approach is used routinely in non-engineering disciplines in undergraduate and graduate courses. Engineering courses use it in graduate and upper level undergraduate courses. However, until the year of 2001, second year engineering technology courses like steel and concrete construction at Penn State Fayette, The Eberly Campus did not use it as a format for the course project preferring the big structure project.

The alternative approach is still being used in these two courses at this campus. An outline of this approach is given next.

\section{Project requirements and criteria}

- The topic must be related to the course.

- The topic should lead to a reasonable project within the scope of the course. In other words, the topic should be neither narrow nor wide open.

- The student should gain extra knowledge from his or her chosen project.

- Classmates should gain extra knowledge from each student's project.

- The instructor needs to learn something new from every project.

- The project consists of a presentation and a report.

- The presentation should be conducted professionally using Power Point, or a similar application.

- The report should be prepared professionally using Microsoft, or similar applications.

The chronology of the adopted approach is as follows.

"Proceedings of the 2005 American Society of Engineering Education Annual Conference \& Exposition Copyright (C) 2005. American Society of Engineering education" 
First week of classes:

The instructor informs his or her students that this course requires a project. The course syllabus reflects this requirement. It officially informs the students that this project carries a certain percentage of their final score. A typical allocation is $30 \%$.

Fourth week of classes:

The instructor gives instructions on the project and its requirements. The instructor explains to the students the benefits of giving them a choice to have their own topics instead of being assigned by the instructor. The instructor encourages the students to do their own independent research to find suitable topics.

At this initial stage, many students encounter some difficulties in choosing a topic. Fortunately, this turns out to be a short-term difficulty. The instructor can easily handle this particular situation. It is important to point out that the instructor should never hand out a topic to any student because that defeats the purpose of the approach to start with. The instructor can however guide the student through possible topics and advise him or her on how to choose a suitable topic. This can be done by meeting with each student on an individual basis. The instructor offers to share parts of previous projects with the students as examples provided that the topics in these examples if shown are not to be used again.

Also at this initial stage, it is common to notice that some students have more than one possible topic to choose from for their projects. The instructor can explain the advantages and disadvantages of each choice in relation to the others. The instructor however does not influence any of his or her students to choose a particular topic. The student is the one who finalizes his or her choice.

First class after the mid-term break:

The instructor officially asks each student to finalize his or her choice for a topic. The instructor makes it an official homework assignment. In this assignment, the instructor asks each student to write a paragraph on his or her topic, and on what he or she intends to do subsequently. The instructor examines every topic very carefully, and meets privately with each student to make sure that the chosen topic meets the project's criteria. If needed, the instructor asks the students to make appropriate revisions to their chosen topics. The instructor and students finalize the topics. Students are ready then to start working on their projects. Between this class and the final week of classes, the instructor periodically checks with his or her students on their progress. He or she offers help to all students. If needed, the instructor can ask for progress reports on a case-by-case basis.

The eleventh hour:

Final preparation takes place in the first part of the last week of classes. The instructor encourages the students to rehearse their presentations. The instructor offers to sit in 
such rehearsal sessions and gives advice and comments to those who choose to practice their presentations. The instructor emphasizes the importance of the presentation. He or she also explains in greater details all of the components needed to deliver a good presentation.

The presentation:

Each student gives a ten-minute presentation during the last class of the semester. Power Point, or a similar application must be used for this presentation. The presentation is followed by a questions and answers session for a few minutes. All students are required to attend all presentations. Other faculty members are invited to attend, and they usually do. Students are strongly encouraged to ask questions. Many students in fact ask questions and provide valuable comments.

The report:

An official report is required. The deadline is the day of the final examination. The report carries the same weight as the presentation itself. As with the presentation, the use of the latest available computer technology is required. This includes but is not limited to Microsoft applications.

\section{The traditional approach within the alternative approach}

An option is available in which the benefits of the traditional and the new approaches are achieved simultaneously. The students are always given the option of designing and detailing a big structure to integrate all of what they learn in weekly short assignments in one big assignment. One student opted for that in one of the steel classes. He designed and detailed a gymnasium. He in fact took it one level higher. He used the drawings for a project in his architectural rendering class. The fact that only one student chose this option in a four-year period demonstrated that students preferred the newly adopted approach to the traditional approach.

\section{Ways in which the alternative approach improves learning}

This alternative approach increases learning in various ways. In some ways, the positive impact is conspicuous and tangible. However, it is not as clear when we look at this approach from different angles. The following is a compiled summary on the ways by which this ownership approach increases learning.

In colleges and universities, engineering educators teach basic theories and concepts to students first. This is followed by basic applications of these theories and concepts. This is supported by the Program Outcomes and Assessment of the ABET Criteria for Accrediting Engineering Programs ${ }^{13}$, and by the Program Outcomes of the ABET Criteria for Accrediting Engineering Technology Programs ${ }^{14}$. It is a reality that instructors do not teach their students all the applications they face in their line of work upon graduation. However, engineering and engineering technology educators indeed prepare the students 
for work by giving them the essential skills and tools they need to perform their work. In his teaching, the author always emphatically informs his engineering and engineering technology students that he teaches them procedures rather than specific problems. Students may never see a particular problem more than once in their lifetime, but they will need to use the same exact procedure many times in their line of work. Indeed, many different real life problems will be solved by the same concept and procedure. That is, students are taught systematic methodologies. Within this framework, students need to learn where and how to find information about what they may encounter in their careers. Further, ABET criteria for accrediting engineering technology programs makes the ability of engagement in lifelong learning a part of its criterion for program outcomes ${ }^{14}$. A major objective for this alternative approach is within this context. Specifically, it gives the students the important skills they need to perform technical research independently. First, they need to identify the resources available to them. This is a learning experience by itself. The students will then explore these resources to complete their projects. In this process, the students learn about many other things besides the topics of their projects. This by itself is also beneficial to their learning process.

Human beings like to have the ability to have a choice over almost everything. This is a natural phenomenon. Steel and concrete students are not exceptions to this rule. Having a choice is obviously not possible in many cases. In many other cases however, it is possible, or it can be made possible. The new approach to the course project creates this possibility. Giving students the privilege of choosing the topics of their projects instills in them the encouragement and motivation to learn more ${ }^{15}$. They enjoy the freedom associated with this approach ${ }^{16,24}$. Further, and based on the author's own observations, this approach gives many students a strong sense of pride as they choose topics, which are related to their lives. For instance, one student chose the topic of "Design and Construction of the New River Gorge Bridge in West Virginia," because he was from the area in which this particular bridge is located. As a second example, another student chose to do his project on "Steel Dumping," because this specific topic had a great influence on the southwestern tip of the Commonwealth of Pennsylvania where our campus is located. All of this has its positive influence on the learning process.

In their daily lives, human beings like to have a sense of ownership over what they do. In fact, this applies to both personal and professional sides of their lives. In the education process, this ownership actually increases productivity because students gain more if they are "actively engaged in their own learning" 15, 17. The adopted approach of assigning the course projects here utilizes this potential and gives the ownership to the students. In return, the students perform better and learn more.

Students are creative in general. Educators need however to create a proper atmosphere to get this creativity out. Giving the students the freedom to choose a topic for their projects and how to proceed subsequently achieves this objective. Students show a lot of creativity in both the presentation and the writing parts of the project.

"Proceedings of the 2005 American Society of Engineering Education Annual Conference \& Exposition Copyright (C) 2005. American Society of Engineering education" 
Students tend to learn from each other about many things in many ways ${ }^{17}$. In fact, they sometimes turn to each other when they do not understand a certain concept from the instructor. They work in teams outside the classroom. Engineering educators should utilize this potential and need to explore ways in which their students teach each other $^{18,24}$. This new approach is designed to achieve this objective. Students learn new things about steel and concrete construction from the projects of their classmates. To meet this expectation, the final exam of the course contains a full question with multiple parts on the students' presentations. Every presentation will have a part in this final exam question. This motivates the students to pay attention to all presentations.

As stated in the project's criteria, each student is required to gain extra knowledge from his or her presentation. It is a fact in almost all courses that the instructor always needs more time to cover more topics or to cover some topics in more details. The new approach partially compensates this by the above requirement. By doing an independent research on a topic of his or her own choice, the student usually learns a lot. Also, much of what the students learn during this process is not suitable to be included in the project. However, this extra knowledge is not a waste. In other words, the students indeed learn more than what they include in their projects. Further, the project should be on a topic, which is not covered in details in the class.

Another important aspect of this new approach lies in the requirement that the instructor needs to gain extra knowledge from each presentation. Initially, this seems unfair to the students because they do not know what exactly the instructor does not know about steel or concrete. In fact, most students expect the instructor to know everything about his or her subject. They fail to realize however that learning is a journey and not a destination according to a famous artist. Close coordination and frequent meetings between the students and the instructor make this requirement possible. The fact that a student teaches his or her instructor something new adds a new dimension to the learning process to both the students and the instructor. The students feel proud that they increase the knowledge of their instructor. The instructor gains new knowledge based on extensive research by his or her students. This also makes the relationship between the instructor and the students more amenable and friendly. All of this improves learning.

The project in these two courses has a limited scope. Nonetheless, it has some research components in it. The term undergraduate research has been used in various capacities. This project promotes several aspects of undergraduate research. The importance of undergraduate research has been well documented in the literature ${ }^{19}$. Many universities have special offices to promote undergraduate research. Undergraduate research makes students "think independently" 20 . This has its positive impact on how students learn. In many cases, undergraduate students themselves realize this importance ${ }^{21}$.

In general, peer pressure has a negative connotation. Nonetheless, a recent research report $^{22,23}$ indicated that peer pressure could be utilized to produce positive results. In the case at hand here, this is done by creating a relaxed atmosphere in which everyone is invited and encouraged to have a contribution.

"Proceedings of the 2005 American Society of Engineering Education Annual Conference \& Exposition Copyright (C) 2005. American Society of Engineering education" 
The engineering industry puts a lot of emphasis on communication skills. It is not surprising to see that almost every job in the engineering business includes excellent communication skills in its list of required qualifications. Communication qualifications include both writing and oral skills. In its criterion for engineering technology program characteristics, ABET also emphasizes the importance of delivering technical reports in effective ways in oral, written, and other suitable formats ${ }^{14}$. The adopted format of the course project aims at instilling such skills in the engineering technology students. The presentation element trains them how to present a professional project in a pleasant and effective way. It alleviates the pressure associated with giving a presentation because it is done in a friendly but serious atmosphere. The report element of the project trains then how to deliver a professional project in writing in a professional manner as well.

Educators in general try their best to keep students motivated in their classes. Students doing independent research in their own manner on the topics they like seems to partially contribute in this regard ${ }^{24}$.

\section{Assessment of the alternative approach from students' perspective}

A formal quantitative assessment on the use of the alternative approach was not made. However, students made numerous and general statements about its implementation. Course evaluations conducted by the administration of the university also contained some comments on this subject.

Most students liked the way in which the project was assigned. They were happy because they were given a choice to pick a topic. Many students said they learned a lot from the project. Many students expressed pride in their work. Many of them considered their work valuable because they asked to get their reports back at the beginning of the following semester or year. Some of them even came back after graduation to pick up their reports.

On the other side, many students complained that they have difficulties finding a suitable topic. This however dissipated fairly quickly as explained earlier. Many students did not like to work independently. Several students did not mind writing a big report, but they did not like to give a presentation. Some wanted to give a presentation without writing a report. By far, the most frequent complaint was on writing the report.

\section{Assessment of the alternative approach from the instructor's perspective}

This approach produced more when it comes to learning. It taught the students how to depend on themselves instead of totally and continuously relying on the instructor.

Further, it gave them the control over a major part of their learning process. However, the instructor needed to allocate more time to his students. Additionally, the instructor had to deal with the students who always complained about how much work they had to perform. In essence, it was a pleasant way of doing business but it came with a price. 


\section{Limitations and constraints}

There are some limitations and constraints associated with the alternative approach. Four such disadvantages have been identified. Some of these difficulties cannot be alleviated, and are therefore inevitable. However, other difficulties may be eased through certain actions.

The most serious difficulty associated with this approach is the fact that the instructor needs to spend a lot of time with his or her students. This approach calls for individualized projects and not a mass production of the same topic. The instructor must spend extra time with each student separately in the initial phase when students choose their topics. The instructor then must respond to each student's needs during the actual preparation time. The instructor sometimes needs to conduct his or her independent research on the students' topics to address raised questions. This follows all the way up to the end when the instructor evaluates the projects individually.

Students have their own difficulty with this approach. Generally speaking and unfortunately, students are trained to take instructions and follow them. That is, they are usually spoon-fed. It takes a lot of effort to pull students from this passive to a more proactive mode. In other words, this approach requires extra time and effort from the instructor and from the students.

Class size can sometimes make the implementation of this approach difficult. The extra time, which the instructor has to spend on dealing with each student for his or her project, increases proportionally with the size of the class. Further, more class periods need to be allocated for the presentations in larger classes. Fortunately, the size of the class in this particular case as can be seen from the list of the projects in the appendices was small. It ranged from four to ten students during the past four years. The author has the opinion that this method of assigning the course projects becomes increasingly impractical once the class size exceeds twenty students.

A potentially dangerous disadvantage to this approach is the real possibility of plagiarism. A smart student can surf the Internet and easily get a paper on a topic on steel or concrete. Unfortunately, there are sites, which legally sell inexpensive term papers. A student can manipulate the purchased paper to fit the required scope of the project. Fortunately, this disadvantage can be easily resolved in this particular case. The close coordination between the instructor and the students in the preparation stages can effectively eliminate this possibility for plagiarism. Requiring the submission of sporadic progress reports if needed makes committing plagiarism much more difficult. Further, the fact that an oral presentation is needed contributes in the prevention of plagiarism. In the four-year period, the author had only one case in which plagiarism was suspected.

\section{Conclusions and recommendations}

An alternative approach of assigning the class project has been used in the steel and concrete construction courses in the Architectural Engineering Technology Program at

"Proceedings of the 2005 American Society of Engineering Education Annual Conference \& Exposition Copyright (C) 2005. American Society of Engineering education" 
Penn State Fayette, the Eberly Campus in the past four years. In essence, the students had an ownership of this project. The students had a lot of freedom on choosing the topics and the execution of the project, while the instructor had supervisory and monitoring roles. This approach enhanced the learning process. This paper outlined the elements of this approach, and it explained its effectiveness. Other instructors who teach similar or other engineering technology courses are encouraged to use this approach. However, they have to be aware of its limitations.

\section{Bibliography}

1. Ogot, M., Elliot, G., and Glumac, N., An Assessment of In-Person and Remotely Operated Laboratory, Journal of Engineering Education, Vol. 92, No. 1, pp. 57-63, January 2003.

2. Foulds, R., Bergen, M., and Mantilla, B., Integrated Biomedical Engineering Education Using Studio-Based Learning, IEEE Engineering in Medicine and Biology Magazine, Vol. 22, Issue 4, pp. 92-100, July/August 2003.

3. Major, C., Implementing Problem-Based Learning in Undergraduate Education, The Journal of General Education, Vol. 51, No. 4, pp. 235-334, 2002.

4. Navaz, H., A New Approach to Teaching Undergraduate Thermal/Fluid Sciences-Courses in Applied Computational Fluid Dynamics and Compressible Flow, International Journal of Mechanical Engineering Education, Vol. 30, Issue 1, pp. 35-49, January 2002.

5. Williamson, K., Resources in Technology, Technology Teachers, Vol. 64, Issue 3, pp. 15-19, November 2004.

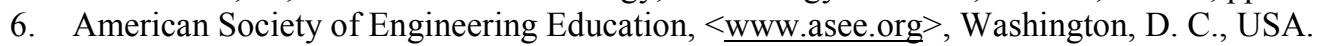

7. Sutterer, K., and Descoteaux, T., Before Senior Design-Integration of Project-Based Learning in Multi-Course Structural Engineering Sequence, Proceedings of the 2002 ASEE Annual Conference and Exposition, p. 1228512292, 2002.

8. Tabatabai-Gargari, M., Project-Based Steel Design Course, Proceedings of the 2004 ASEE Annual Conference and Exposition, p. 11537-11546, 2004.

9. Hipp, J., Course Syllabus for Sociology 114: The City and Urbanization at the Department of Sociology at the University of North Carolina at Chapil Hill, $<$ http://www.unc.edu/courses/2002fall/soci/114/001/Paper.html>, Fall 2002.

10. Mitchell, Course Syllabus for English 123: College Research Paper at the Department of English at the University of Northern Colorado, $<$ http://www.unco.edu/che/syllabi/eng123/mitchell2005.pdf $>$, Spring 2005.

11. McMullin, K., Course Syllabus for CE 163 - Design of Steel Structures at the College of Engineering at San Jose State University, <http://www.engr.sjsu.edu/mcmullin/courses/ce163>, Spring 2002.

12. Belarbi, A., Syllabus for CE 327 - Advanced Concrete Structure Design at the Department of Civil Engineering at the University of Missouri-Rollal, Winter 2005.

13. Accreditation Board for Engineering and Technology, Criteria for Accrediting Engineering Programs, 20042005 Cycle, Baltimore, Maryland, ABET Inc., 2004.

14. Accreditation Board for Engineering and Technology, Criteria for Accrediting Engineering Technology Programs, 2004-2005 Cycle, Baltimore, Maryland, ABET Inc., < $<$ www.abet.org $>, 2004$.

15. Bradford, M., Motivating Students Through Project-Based Service Learning, The Journal Online Magazine, $<$ http://www.thejournal.com/Magazine $>$, January 2005.

16. Brooks, S., Freiberger, S., and Grotheer, D., Improving elementary student engagement in the learning process through integrated thematic instruction. Unpublished Master's thesis, Saint Xavier University, Chicago, 1998.

17. Harris, R., Some Ideas for Motivating Students, Virtual Salt, <http://www.virtualsalt.com> March 2, 1991.

18. Strong, R., Silver, H., and Robinson, A., What do students want?, Educational Leadership, Vol. 53, No.1, p. 812, 1995.

19. Hecker, L., Majoring in Biology Just Isn’t Enough, BIOS, Vol. 73.2, 2002.

20. Schwartz, M., The Role of Advising in Undergraduate Research, The Mentor: An Academic Advising Journal, September 16, 2003.

21. Laroche, K., Advantages of Undergraduate Research: A Student's Perspective, Eye on Psi Chi, Vol. 8, No. 2, pp. 20-21, Winter 2002.

"Proceedings of the 2005 American Society of Engineering Education Annual Conference \& Exposition Copyright (C) 2005. American Society of Engineering education" 
22. Hall, K., UCSB Teaching Assistant Development Program, University of California Santa Barbara, $<$ http://www.oic.id.ucsb.edu/Ta $>$, February 2005.

23. Hsu, P., The Effect of Peer Modeling on Taiwanese College Students' Self-Efficacy and Reading Performance in English Class, Dissertation Abstracts International, Humanity and Social Sciences, Section A, Vol. 60, p. 2798, March 2000.

24. Brewster, C., and Fager, J., Increasing Student Engagement and Motivation: From Time-on-Task to Homework, Prtland Oregon, Northwest Regional Educational Laboratory, October 2000.

\section{Biography}

Aiman S. Kuzmar is an assistant professor of engineering at Penn State Fayette, the Eberly Campus. He holds a Ph. D. degree from Duke University. He has a Master's degree from Rice University. His B. S. is from the University of Petroleum and Minerals in Saudi Arabia. All of His degrees are in civil engineering. His industrial experience includes working as an Engineer for the NCDOT. He is a registered engineer in North Carolina.

\section{Appendix A: List of projects in the Steel Construction course}

Fall 2002

- Structures, Procedures - Design - Plans Presentation

- Design and Construction of the New River Gorge Bridge in West Virginia

- Steel Framing Timeline

- Structural Steel Design of Penn State Fayette Gymnasium Renovation

- Corrosion Prevention

- Petronas Towers

- Devils's Elbow Bridge

- The Steel Dumping Crisis in the United States

- Stress Corrosion/ Corrosion Fatigue, Why the Silver Bridge at Point Pleasant, West Virginia Had Failed

- Behavior of Structural Steel under Fire Conditions

Fall 2003

- Modus Operandi: Steelmaking

- Corrosion in Structures

- Stainless Steel

- Steel Dumping

- The History of Steel in Western Pennsylvania

- Steel Making

- Quebec Bridge: a Failure of Enormous Size

- Fireproofing Steel

- Corrosion 
Fall 2004

- The Basic Oxygen Process

- SMAW- Shielded Metal Arc Welding

- Steel Recycling

- Stainless Steel

- Pre-Engineered Buildings

- Effects of Fire on Structural Steel and Products That Can Protect It

- The Brooklyn Bridge

- The Bessemer Process

\section{Appendix B: List of projects in the Concrete Construction course}

Spring 2001

- The use and Design of Concrete Footings

- Construction of the Sydney Opera House

- A New Engineering Building, the Reinforced Concrete Design Process

- Concrete Construction of the Hoover Dam

Spring 2002

- The Collapse of the Tacoma Narrows Bridge

- Monolithic Domes

- Concrete Homes

- Fiber Reinforced Concrete

- Hollow Core Blanks

- Concrete Corrosion, the Cause and the Effect

- Concrete Corrosion

- Fly Ash

- Masonry Walls

Spring 2003

- Concrete Recycling

- Fly Ash in Concrete

- Nondestructive Testing of Structural Concrete

- The Bang Na Expressway: the World's Largest Concrete Precasting Operation

- Nondestructive Concrete Testing

- Geodesic Dome Homes

- Silica Fume

- Falling Water: the Sagging Concrete

- Hoover Dam 
Spring 2004

- The Recycling of Concrete

- Corrosion of Steel in Concrete

- Concrete Admixtures

- American Concrete Institute (ACI) Certification Programs

- The Hoover Dam

- Fly Ash Concrete

- Air-Entraining Concrete

- Portland Cement 